\title{
Welding Analysis and Optimization of Ultra- Sonic Welding in HDPE- 5\%PBI Composite by CODAS Decision-Making Approach
}

\section{Ramesh M}

Panneerselvam Kavan ( $\boldsymbol{\nabla}$ kps@nitt.edu )

National Institute of Technology Tiruchirappalli https://orcid.org/0000-0002-9231-7122

\section{Research Article}

Keywords: HDPE composite, Ultrasonic welding, ANOVA, CODAS, Weld morphology

Posted Date: February 28th, 2022

DOI: https://doi.org/10.21203/rs.3.rs-1391025/v1

License: @ (1) This work is licensed under a Creative Commons Attribution 4.0 International License. Read Full License 


\section{Abstract}

Engineering plastics are increasingly being used in structural and non-structural applications. As the need for plastics grows, so do the joining requirements. Ultrasonic welding is one of the favoured processes for polymer composites among numerous approaches, especially for bonding plates, automotive panel boards and couplings due to its joint quality and low cost. The High-density polyethylene (HDPE) matrix was reinforced with 5 wt.\% of polybenzimidazole (PBI) fibre by twin screw extrusion process and welding samples were prepared using injection moulding. In this study, Ultrasonic welding was used to connect 4-mm-thick lapped HDPE-5wt. \% PBI composites. Taguchi-based L27 orthogonal array was employed for experiments to study the lateral shear strength (LSS) and Shore-DHardness for the input parameters (i) weld duration (30,45 and $60 \mathrm{~ms})$, (ii) Amplitude (19,20 and $21 \mathrm{~Hz}$ ) and (iii) Horn pressure (1.5,2 and 2.5 MPa). The relevance of the parameters affecting shear strength and hardness of weld was studied using analysis of variance (ANOVA). The ultrasonic welding process was carried out, and the multi-criteria decision-making (MCDM) approach was used to optimise the process parameters. To determine the optimal amount of input parameters for multi-objective optimization criteria on Shear strength and Shore D Hardness, entropy approach weights $0.5,0.5$ are combined with combinative distance-based assessment (CODAS) technique. From CODAS assessment the relative evaluation score of 2.444 was achieved by the twenty fifth experiment having the input parameters (IP) at $60 \mathrm{~ms}$ welding time, Amplitude of $21 \mathrm{~Hz}$ and Pressure at $2.5 \mathrm{MPa}$. Fractography and weld morphology of welded joints were investigated using scanning electron microscope (SEM).

\subsection{Introduction}

In recent decades, industries have generally embraced ultrasonic welding of thermoplastics and it is still widely recognised as a very efficient technology that results in no polymer degradation. Ultrasonic welding is utilised in the packaging industry, for automotive panels, textiles, appliance manufacturing, etc. [1-4]. The process of joining the composites is crucial in the manufacturing process of fibre-reinforced thermoplastic composites for structural purposes. While conventional joining solutions such as mechanical fastening and adhesive bonding are conceivable, they are not optimal since they might result in a range of structural abnormalities, such as stress concentration and fibre breaking in the case of mechanical fastening, as well as increased susceptibility to temperature, moisture, and other environmental factors in the case of adhesive bonding. These irregularities could ultimately lead to a reduction in the structural performance of the structure. [5-8]

Fusion welding may be accomplished by the use of a variety of plastic welding processes. These welding procedures are classified according to the method used to provide heating elements at the anticipated bond point. Friction welding, which includes vibration, spin, stir, and ultrasonic welding techniques, is a well-known kind of fusion bonding. To solve the disadvantages of adhesive bonding, particularly the complexity of the heating process, alternative heating and curing technologies such as vibration, resistance, microwave, induction, and ultrasonic welding may be used.

When it comes to connecting thermoplastics, ultrasonic welding has been shown to be a viable option among all of the fusion methods tested. The intermolecular interaction between the thermoplastics induced by ultrasonic vibrations causes intermolecular diffusion and trapping of the molecular chain within the liquid state on the interfaces of the weld polymer in this approach, which is a distinguishing property. [9-17]

When it comes to ultrasonic welding polymeric systems, semi-crystalline and amorphous thermoplastics are considered superior raw materials to crystalline thermoplastics. Nevertheless, energy directors (EDs) are often made by utilising compression or injection moulding techniques on a single mated thermoplastic specimen in order to localise ultrasonic vibrations to the bonding zone. However, thermosets are difficult to weld ultrasonically.[18, 19] Yousef Pour et al. offered an overview of several thermoplastic joining procedures [20]. They discussed several fusion bonding processes, as well as associated equipment, manufacturing methodologies, the influence of technical parameters on welded joints, and their applications. Nonhof et al. [21] proposed a four-step procedure for doing ultrasonic welding. These stages have resulted in a variety of phenomena when polymers are ultrasonically welded. An effort to mimic thermoplastic ultrasonic welding was made by Suresh et al. [22]. When ultrasonically welding thermoplastics, they employed viscoelastic heating as the major heating technique. The simulated findings are consistent with the temperatures measured during ultrasonic welding. In comparison to other EDs, TRI ED exhibits high temperature zones and higher ultimate tensile strengths (UTS). In spite of this, the number of experiments appears to be insufficient in depth and breadth in terms of ultrasonic welding thermoplastics. Villegas et al. [23] investigated the impact of various energy directors' orientation and arrangement on their performance. While TRI ED has a significant impact on weld quality, this study only uses polyetherimide as an example of the material. Tsujino et al. [24, 25] investigated the welding properties of ultrasonic welding machines employing a range of frequency settings. The increased joint 
strength is achieved by employing $67 \mathrm{KHz}$ welding equipment rather than 20 or $40 \mathrm{KHz}$ welding equipment. Again, the effects of other weld parameters (ED, amplitude, pressure, etc.) on weld strength were not explored in this study. Additionally, plastic welding has been performed using a variety of ultrasonic welding techniques, but the thickness of the specimens appears to be extremely thin.

Additionally, the energy director has not been employed for thermoplastic welding. Thus, it is necessary to consider all weld parameters in order to have a sound knowledge of the ultrasonic welding process for plastics. Research conducted by A. V. Aaken and C. Hopmann $[26,27]$ sought to assess the impact of moisture on the process-material interaction during ultrasonic welding. They conducted their investigation using polyamide, which is extremely hygroscopic. Despite what the authors say is the best way to study ultrasonic welding of plastics, this study only looked at one weld parameter (welding time) for how it changed with moisture levels.

The design of parameters is critical to achieving both good quality and affordable cost. We may achieve a large number of results from a small number of studies using the Design of Experiments (DOE). The ANOVA approach is commonly used to determine the significance of each factor [28]. The analysis of variance reveals that the most important weld component affecting the welding quality is the hardening time. Chang et al. [29] employed experimental design to gain a thorough grasp of vibration and ultrasonic welding of thermoplastic polyolefins. If two thermoplastic polymers are used, ultrasonic welding may appear to have a greater weld strength than vibration welding.

As part of their prior research, Liu and his colleagues [30-33] looked at how to improve ultrasonically welded thermoplastics' bond strength. When linking virgin polypropylene and $10 \%$ glass fibre reinforced polypropylene composites, triangular energy directors were found to have the best strength, while when joining $30 \%$ glass fiber-filled composites, a semi-circular energy director had the highest strength. The researchers discovered that SEMI ED provided the strongest welds. Welding thermoplastics like HDPE and acrylonitrile butadiene styrene (ABS) can be improved by using fractional factorial design (ABS). They discovered that welding duration and pressure had a substantial effect on joint strength. Although Liu and Rani investigated how to optimise weld strength when thermoplastics are employed, they used the same Philips sample shape. As a result, weld strength optimization may be accomplished through the use of enhanced and novel sample shapes [34].

In addition to butt joints, ultrasonic welding was employed to link the lapping workpieces with energy directors. Ultrasonic weld energy is directed by an energy director to a smaller region of contact, which increases weld quality and speed. While the energy director may increase the resilience of the process, it is possible that the horn was unable to identify the energy director in the manufacturing environment, making component assembly more difficult. There will be less complexity in the process if an energy director isn't needed for ultrasonic welding of parts that are lapped.[35]

The goal of this investigation was to see if a 4-mm-thick PBI-reinforced HDPE composite without the need for an energy director could be successfully welded using ultrasonic welding. Part one covers the experimental process, which includes the materials, experimental setup, sample production and testing, mechanical testing, and fractography analysis. It continues with a look at how welding factors affect bond strength and failure mechanisms in UW joints, as well as how weld growth mechanisms work and a way to predict the welding window. Experimental testing of ultrasonic welding lapped joints with nominal weld schedules yielded the fractography of the welds. Ultrasonic welding can be used to fuse HDPE/PBI composites that have been lapped together.

With a few exceptions, the majority of the studies employed standard optimization techniques such as GRA and RSM for multi-objective optimization. Until now, the MCDM method of the combinative distance-based assessment (CODAS) technique has not been used to optimise the weldability of HDPE/PBI composites on a multi-objective basis. According to the industries, CODAS is typically used in the aerospace and automotive sectors, as well as in applications that demand a high-quality weld but are difficult to build using conventional techniques. Certain geometrical quality characteristics must be addressed in order to achieve a stronger weld connection. A parametric analysis was carried out to identify the influence of various welding control factors on the quality metrics of HDPE/PBI composites, such as lap shear strength (LSS) and Shore D hardness. We were able to enhance the welding qualities by utilising ultrasonic welding equipment with suitable parameter settings. Multi-objective optimization was examined using the MCDM methodology, which is a component of the CODAS method [36]. A comparison of CODAS relative findings was conducted in order to determine the best possible outcomes. It was feasible to forecast and change process factors that affect the weld quality of HDPE/PBI composites using the CODAS approach, which is based on MCDM. As a consequence, the lap shear strength output characteristics were enhanced.

\subsection{Materials}


HDPE granules with grade name REPOL HD50MA180 was purchased from Reliance India, Ltd and used as a matrix in the current study. MERCK, India Ltd supplied the PBI particles with the grade name of GAZOLE 5000 having $485^{\circ} \mathrm{C}$ glass transition temperature. HDPE 5wt. \% PBI was found with enhanced mechanical properties.

\subsection{FABRICATION OF HDPE/PBI COMPOSITE}

In this work, HDPE/PBI composites were made and evaluated. Preheating the PBI (Poly (2, 5 benzimidazole) powder for 6 hours and the high-density polyethylene (HDPE) pellets for 2 hours in an $80^{\circ} \mathrm{C}$ hot air oven. Preheating was used to eliminate moisture from the raw ingredients, as moisture impairs the performance of plastics. A volumetric form feeder is used to combine HDPE and PBI nanoparticles into the twin screw extruder. The HDPE pellets and PBI powder are interlaced using the Flytech Engineering FUE-2EA twin screw extruder at a length to diameter ratio of 40:1. To achieve constant distribution, the screw speed was adjusted at $65 \mathrm{rpm}$ and the volumetric feeder speed to $6 \mathrm{rpm}$. The Twin screw extruder temperature profiles ranging from $130^{\circ} \mathrm{C}$ to $195^{\circ} \mathrm{C}$ for this investigation. To mesh the PBI powder with HDPE granules uniformly, various screw pitches and equipment such as kneading blocks were used. The filament is fed through a pelletizer machine, which converts the HDPE/PBI blend into $3 \mathrm{~mm}$ granules. The HDPE-5\% PBI test specimens for this welding study were manufactured using an injection moulding machine. Ultra-sonic welding was done on the manufactured samples with various parameters to obtain the best result for the weld as shown in Fig. 1.

Table 1

Properties of HDPE-5\% PBI composite

\begin{tabular}{|ll|}
\hline Tensile Strength (MPa) & $\mathbf{2 7 . 4} \mathrm{MPa}$ \\
\hline Flexural strength & $26 \mathrm{MPa}$ \\
\hline Flammability & $19 \mathrm{~mm} / \mathrm{min}$ \\
\hline Density & $0.986 \mathrm{~g} / \mathrm{cc}$ \\
\hline Shore D Hardness & 75 \\
\hline
\end{tabular}

\subsection{Characterization of USW processed HDPE-5\%PBI joints.}

In accordance with ASTM D638-14, tensile tests on the USW joints were performed utilising a computerised tensometer. The shore D hardness tester was used to conduct the test, which was conducted in accordance with ASTM D2240-05. Each test was carried out five times for each set of parameters, with the average of the results being taken into consideration. The metallurgical characterization of USW joints was investigated using a scanning electron microscope.

\subsection{Results And Discussions}

\subsection{Microstructure Examination}

Analyses of produced specimens showed high-intensity peaks of carbon peaks and low-intensity ones for other elements including silicon, oxides and calcium. EDS investigation revealed that PBI fibres contain silica with a low-intensity peak in their chemical composition. It was found that $\mathrm{Si}, \mathrm{C}$, and $\mathrm{O}$ had high intensity peaks. Twin screw extruder was used to evenly spread secondary reinforcement particles throughout the material's manufacture, as confirmed by EDS. Element mapping of HDPE-5\% PBI composite is seen in the SEM images shown. The component base metal has larger concentrations of some elements, such as $\mathrm{C}$, as revealed by the EDS study. The spectra showed that HDPE's Matrix material contained Si and Ca. Secondary particles might be seen in the form of lowintensity peaks.

Table 2

Elements present in the HDPE-5\% PBI composite.

\begin{tabular}{|lllll|}
\hline Element & Weight \% & Atomic \% & Error \% & K ratio \\
\hline C K & 93.30 & 95.35 & 2.51 & 0.8490 \\
\hline O K & 5.49 & 4.21 & 13.73 & 0.0083 \\
\hline SiK & 0.54 & 0.24 & 15.52 & 0.0045 \\
\hline CaK & 0.67 & 0.20 & 18.67 & 0.0058 \\
\hline
\end{tabular}

Page $4 / 17$ 


\subsection{The interaction of input variables on the behaviours of the output}

Typical welding frequencies range from the $40 \mathrm{KHz}$ range to the $15 \mathrm{KHz}$ range. The various parameters of the application will determine the best equipment and frequency to achieve an optimal weld for the parts. The $20 \mathrm{KHz}$ frequency is the most commonly used ultrasonic frequency for plastics assembly and offers maximum flexibility, as it is suitable for a wide range of applications and thermoplastic components.

Investigations had been carried out to determine whether the hold time is a factor to be considered for the weld strength of composite joints. Increased weld strength was seen as a result of extending the hold duration, which was shown to be beneficial until optimal values were obtained. When the two pieces of material are in contact under ultrasonic welding process the molecular contact occurs at the melting state at fusion zone. The inter diffusion of the polymeric chains during the due to the vibration resulting in the formation of fusion bond between the two pieces. The samples are placed under certain pressure for a period of time. This procedure involved freezing the molten polymers just before they contacted each other on each side of the joint. It is natural for a semi-crystalline polymer to recrystallize as it cools. When you apply sustained pressure to a melt for an extended length of time, the polymer's molecular chains are capable of penetrating the joint interface and become intertwined with chains on the opposite side of the contact as shown in image. This is called entanglement. This gives molecular chain formation and the joint strength will both greatly increase in magnitude as a result of this development.

\subsubsection{Welding pressure influence on LSS \& Shore D Hardness}

As a result of the welding process, the samples are subjected to a weld pressure, which causes the energy to flow in one direction and the components fuse together. When the weld pressure is applied over an extended period of time, the polymer's molecular chains are able to pierce the joint contact and intertwine with chains on the opposite side of the joint. As a consequence of this, both the connectivity of the molecular chains and the shear strength of the components are greatly enhanced. As a result of the hold pressure, the tangling of molecular chains at the weld junction increases, resulting in increased joint strength as shown in Fig. 3. Too low hold pressure results in improper flow of molten material. Molecular alignment occurs transverse to the weld surface as a result of an excessive amount of pressure, resulting in a weakening of the weld.

\subsubsection{Amplitude influence on LSS \& Shore D Hardness}

For HDPE/PBI composites, the most essential factor was amplitude, which provided a greater proportion to the final result than weld length or Horn pressure did separately. The frequency, time period and amplitude of an ultrasonic vibration all have a role in the significance of the vibration. The amplitude of ultrasonic vibrations is increased, which causes the molecules that make up a polymer to vibrate more vigorously. It is induced by the molecules rubbing against one another during molecular vibration that the frictional heat is produced. The amount of frictional heat produced rises as the amplitude of the vibration increases. Because of frictional heat, thermoplastics may melt more quickly. Increased vibration amplitude results in a considerable increase in the quantity of energy taken in as well as the strength of the weld. Because crystalline materials need a larger amount of energy to melt and weld than non-crystalline materials, as previously stated in the introduction, this is most likely owing to the higher quantities of energy required for melting and welding. The quantity of energy wasted by a vibration is proportional to the square of the amplitude of the wave. Additional benefits of lengthening your welding process include increased energy dissipation, which should result in an improvement in the strength of your weld. The frequency and duration of an ultrasonic vibration are well-known constants. The amplitude was adjusted to 19,20 , and $21 \mathrm{~Hz}$ in this study. A constant and enough supply of molten material at the anticipated weld contact is essential for an optimal LSS value. Because of the large amplitudes, a significant amount of molten material is utilised to start the weld. An equal distribution of molten material under pressure results in an appropriate heat affected zone (HAZ) and an improved life span. As a result, the supply of molten material (HDPE composite) may be tightly controlled by applying varied amplitude and pressure levels. The SEM images shown in Fig. 3a,b \&c also reveals the changes in surface due to different amplitude vibrations.

\subsubsection{Weld time influence on LSS \& Shore D Hardness}

Semi-crystalline thermoplastic HDPE/PBI composite has a melting point of 135 degrees Celsius. The specimens are ultrasonically welded with enough ultrasonic energy. The HDPE composite's characteristics will decline if the weld duration is too long, therefore kept it to a minimum. The less time it takes to weld, the fewer cycles of vibration the specimens are subjected to. It takes a specific length of time for the vibrations to develop frictional heat, which is necessary for the weld connection to be formed. When ultrasonic vibrations are given to specimens, heat energy dissipates, and this is reflected in the loss modulus. The out-of-phase component of a complex modulus is another name for the loss modulus. Furthermore, heat distortion temperature (HDT) is defined as the rate at which a material 
deforms at a certain temperature. A high amount of welding time, then, ensures that the best LSS may be achieved. The majority of the time, plastics become tangled up in each other. The topological constraints (TCs) that regulate the viscoelastic and plastic changes are called entanglements. In most cases, these interfacial entanglements increase the bond strength and reduce the likelihood of a chain pull-out failure mode.

\subsection{Analysis of Variance for Ultra-Sonic Welding Joints}

Using ANOVA, researchers may examine the correlation between input variables and output variables. The Fisher test is used to determine the rate of significance of the input variables, and it is utilised to do so (F-test). The workpiece feed rate, tool profile, and vibrating tool frequency were all examined as input factors.

Table 3

Input parameters and their corresponding output responses

\begin{tabular}{|c|c|c|c|c|c|c|}
\hline Sl.no & Weld time (ms) & Amplitude $(\mathrm{Hz})$ & Pressure (MPa) & Shear strength (N/mm2) & Shore D Hardness & Weld Energy (J) \\
\hline L1 & 30 & 19 & 1.5 & 13.23 & 33 & 114 \\
\hline L2 & 30 & 19 & 2 & 13.68 & 35 & 152 \\
\hline L3 & 30 & 19 & 2.5 & 13.74 & 38 & 190 \\
\hline L4 & 30 & 20 & 2.5 & 13.88 & 42 & 200 \\
\hline L5 & 30 & 20 & 1.5 & 13.38 & 34 & 120 \\
\hline L6 & 30 & 20 & 2 & 13.65 & 37 & 160 \\
\hline L7 & 30 & 21 & 2 & 14.36 & 37 & 168 \\
\hline L8 & 30 & 21 & 2.5 & 14.52 & 40 & 210 \\
\hline L9 & 30 & 21 & 1.5 & 13.86 & 33 & 126 \\
\hline L10 & 45 & 19 & 2.5 & 14.12 & 38 & 285 \\
\hline L11 & 45 & 19 & 1.5 & 13.24 & 32 & 171 \\
\hline L12 & 45 & 19 & 2 & 13.82 & 36 & 228 \\
\hline L13 & 45 & 20 & 2 & 14.3 & 41 & 240 \\
\hline L14 & 45 & 20 & 2.5 & 14.35 & 43 & 300 \\
\hline L15 & 45 & 20 & 1.5 & 13.66 & 39 & 180 \\
\hline L16 & 45 & 21 & 1.5 & 13.83 & 40 & 189 \\
\hline L17 & 45 & 21 & 2 & 14.26 & 43 & 252 \\
\hline L18 & 45 & 21 & 2.5 & 14.43 & 45 & 315 \\
\hline L19 & 60 & 19 & 2 & 14.24 & 43 & 304 \\
\hline L20 & 60 & 19 & 2.5 & 14.19 & 43 & 380 \\
\hline L21 & 60 & 19 & 1.5 & 13.72 & 38 & 228 \\
\hline L22 & 60 & 20 & 1.5 & 14.06 & 41 & 240 \\
\hline L23 & 60 & 20 & 2 & 14.45 & 44 & 320 \\
\hline L24 & 60 & 20 & 2.5 & 14.72 & 47 & 400 \\
\hline L25 & 60 & 21 & 2.5 & 15.17 & 48 & 420 \\
\hline L26 & 60 & 21 & 1.5 & 14.61 & 44 & 252 \\
\hline L27 & 60 & 21 & 2 & 14.95 & 45 & 336 \\
\hline
\end{tabular}


Table 4

Analysis of Variance for Shear strength $(\mathrm{N} / \mathrm{mm} 2)$

\begin{tabular}{|lllllll|}
\hline Source & D.F & Adj S.S & Adj M.S & $\mathbf{F}_{\text {cal }}$ & $\mathbf{F}_{\text {Table }}$ & Contribution (\%) \\
\hline Weld time $(\mathrm{ms})$ & 2 & 1.98112 & 0.9905 & 107.4 & 4.46 & 31.6 \\
\hline Amplitude $(\mathrm{Hz})$ & 2 & 2.02787 & 1.0139 & 110.0 & 4.46 & 32.39 \\
\hline Pressure $(\mathrm{MPa})$ & 2 & 1.83494 & 0.9174 & 99.53 & 4.46 & 29.3 \\
\hline Weld time $(\mathrm{ms}){ }^{\star}$ Amplitude $(\mathrm{Hz})$ & 4 & 0.30257 & 0.0756 & 8.21 & 3.84 & 4.83 \\
\hline Amplitude $(\mathrm{Hz}) \star$ Pressure $(\mathrm{MPa})$ & 4 & 0.00961 & 0.0024 & 0.26 & 3.84 & 0.16 \\
\hline Weld time $(\mathrm{ms}) \star$ Pressure $(\mathrm{MPa})$ & 4 & 0.03104 & 0.0077 & 0.84 & 3.84 & 0.5 \\
\hline Error & 8 & 0.07374 & 0.0092 & - & - & 1.17 \\
\hline Total & 26 & 6.26090 & - & - & - & 100 \\
\hline M.S- Mean sum of squares, D.F- Degrees of freedom and S.S-Sum of squares, & \\
\hline
\end{tabular}

According to Table 4, the most important parameters for determining shear strength $(\mathrm{N} / \mathrm{mm} 2)$, the analysis of variance shows that weld time (ms), Amplitude ( $\mathrm{Hz})$, and pressure ( $\mathrm{MPa})$ are crucial because experimental outcomes that provide F-values that are greater than those obtained using statistical values, are $F(2,8,0.05)=4.46$. Vibrating tool Amplitude contributes 32.39 percent of the total weight of a vibrating tool. There is a 31.6 percent and 29.3 percent contribution from the Welding time (ms) and Pressure (MPa) to this percentage. Interaction is significant only when weld duration $(\mathrm{ms}) \times$ amplitude $(\mathrm{Hz})$ is compared to the F-table value of $F(4,8,0.05)=3.84$, since the F-values estimated for interaction is 8.21 , which is greater than the F-table value. The R-squared score is $98.82 \%$. The interaction plot graph as shown in Fig. 4 reveals the parameter interaction of weld time (ms), Amplitude (Hz), and pressure (MPa) for improvement of shear strength.

Table 5

Analysis of Variance for Shore D Hardness

\begin{tabular}{|lllllll|}
\hline Source & D.F & Adj S.S & Adj M.S & $F_{\text {cal }}$ & $F_{\text {Table }}$ & Contribution (\%) \\
\hline Weld time $(\mathrm{ms})$ & 2 & 228.741 & 114.37 & 123.52 & 4.46 & 45.11 \\
\hline Amplitude $(\mathrm{Hz})$ & 2 & 96.074 & 48.037 & 51.88 & 4.46 & 18.95 \\
\hline Pressure $(\mathrm{MPa})$ & 2 & 139.185 & 69.593 & 75.16 & 4.46 & 27.46 \\
\hline Weld time $(\mathrm{ms}){ }^{\star}$ Amplitude $(\mathrm{Hz})$ & 4 & 29.481 & 7.370 & 7.96 & 3.84 & 05.81 \\
\hline Amplitude $(\mathrm{Hz}) \star$ Pressure $(\mathrm{MPa})$ & 4 & 2.370 & 0.593 & 0.64 & 3.84 & 0.467 \\
\hline Weld time $(\mathrm{ms}) \star$ Pressure $(\mathrm{MPa})$ & 4 & 3.704 & 0.926 & 1.00 & 3.84 & 0.73 \\
\hline Error & 8 & 7.407 & 0.926 & - & - & 1.46 \\
\hline Total & 26 & 506.963 & - & - & - & 100 \\
\hline M.S- Mean sum of squares, D.F- Degrees of freedom and S.S-Sum of squares & \\
\hline
\end{tabular}

Table 5 shows the ANOVA for the shore $D$ hardness of ultrasonic welding joints. The Weld time (ms), Amplitude (Hz) (vibration frequency), and Pressure (MPa) of the Horn are critical parameters, as the F-test values estimated using experimental data are 123.53, 51.88 , and 75.16 , which are higher than the F-test values computed using statistical methods, $F(2,8,0.05)=4.46$. The weld time (ms) required by the horn to processing the vibration for the weld is regarded to be the most critical factor, accounting for $45.11 \%$ of the total. Amplitude $(\mathrm{Hz})$ and Pressure (MPa) contribute 18.95 percent and $27.46 \%$, respectively. The interaction's F-table value is $F(4,8,0.05)=$ 3.84 , and it is significant only in the Weld time $(\mathrm{ms}) \times$ Amplitude $(\mathrm{Hz})$ instance, since the interaction's F-values are 5.81 , which is greater than the F-table value. Its R-square value is $98.54 \%$. The interaction plot graph as shown in Fig. 5 reveals the parameter interaction of weld time (ms), Amplitude ( $\mathrm{Hz})$, and pressure $(\mathrm{MPa})$ for improvement of shear strength. 
Table 6

Relative assessment score and Ranking of output responses based on CODAS system

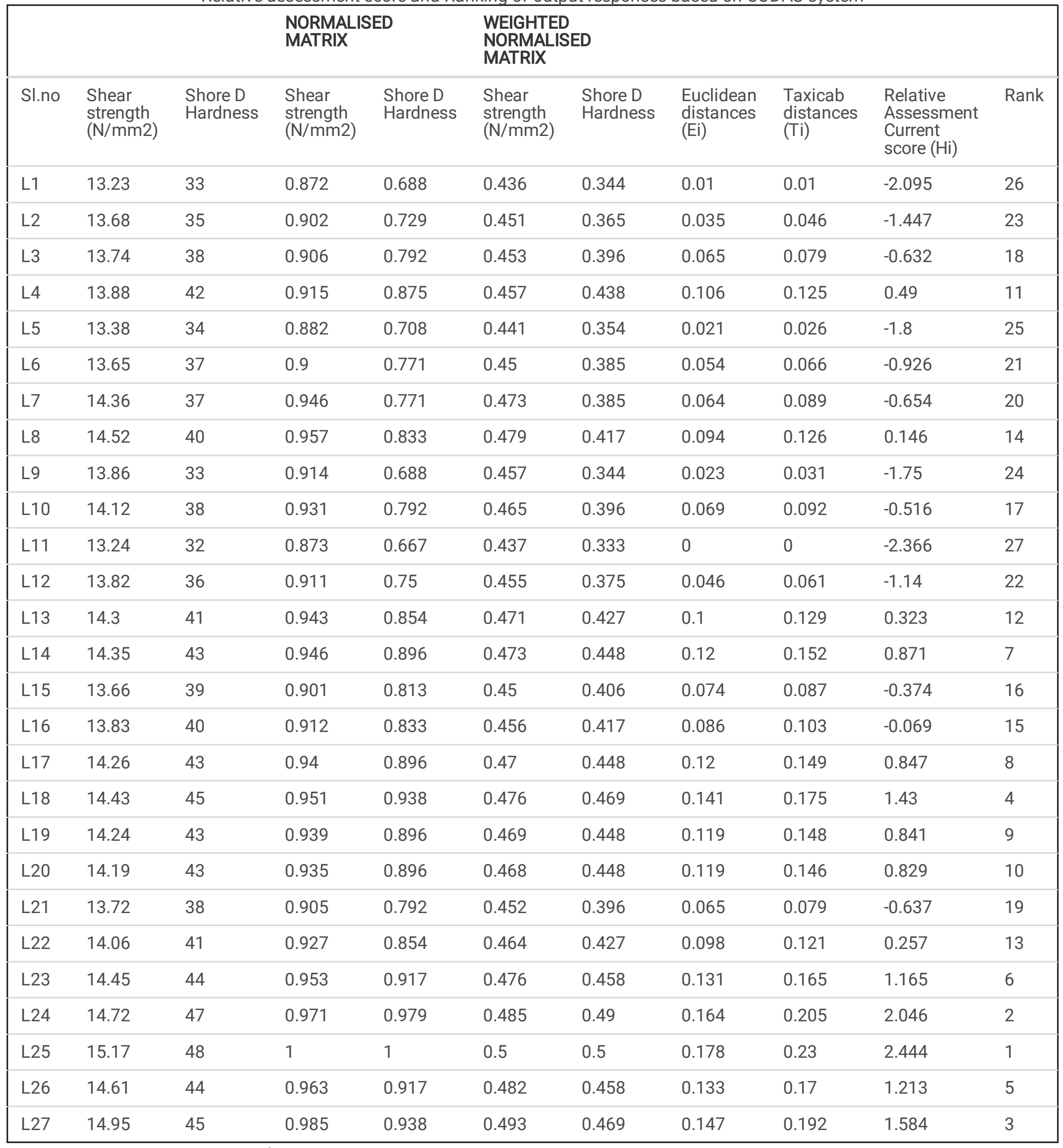

CODAS incorporates entropy weights into its optimization process.

Evaluation of weights for MCDM issues is carried out using the entropy approach, which is employed when the information of the decision matrix is available. C.E. Shannon introduced the Entropy theoretical concepts in 1948, and it has been in use ever since. The three primary weighing methods are subjective, objective, and integral weighting methods, respectively. When evaluating the weights for MCDM issues, the objective Entropy weighting method is utilised. Process parameters were determined using MCDM approaches, which involved evaluating the alternatives based on how well they performed or how well they produced the desired results. Schematic 
approach of the study is shown in Fig. 6 . The following equation describes the entropy weights that are included with the CODAS system.

\section{Step1}

The decision matrix's normalisation $\left(\mathrm{M}_{\mathrm{ij}}\right)$

$$
M_{i j}=\frac{\alpha_{i j}}{\sum_{i=1}^{m} \alpha_{i j}}
$$

3

(ie $\{1,2, \ldots n\},(j \in\{1,2, \ldots m\}) ; a_{i j}$ - of $i^{\text {th }}$ attribute on $j^{\text {th }}$ criterion performance value

\section{Step 2}

entropy calculation of the matrix

$$
S_{j}=-k \sum_{i=1}^{m} M_{i j} \ln M_{i j}
$$

4

Wherek $=1 / \ln (\mathrm{m})$.

\section{Step3}

determining the entropy of a system

$$
W_{j}=\frac{1-S_{j}}{\sum_{j=1}^{n}\left(1-S_{j}\right)}
$$

5

Where Wj- weights criteria

\section{Optimization using CODAS Technique}

The CODAS technique is used to determine the attractiveness of qualities using a ranking system. Calculation of the Euclidean and Taxicab distances between qualities with higher distances from the negative-ideal solution. There might be two distinct metrics. Primary distance is the Euclidean distance; secondary distance is the Taxicab distance. There are $\mathrm{n}$ choices and $\mathrm{m}$ criteria.

The CODAS approach was used to apply MCDM concepts to the selection of material handling equipment.

The following equation illustrates the phase for CODAS techniques.

Step 1. The formation of a decision matrix $(X)$

$$
X-\left[\alpha_{i j}\right]_{n X m}=\left[\begin{array}{cccc}
x_{11} & x_{12} & \cdots & x_{1 m} \\
x_{21} & x_{22} & \cdots & x_{2 m} \\
\vdots & \vdots & \vdots & \vdots \\
x_{n 1} & x_{n 2} & \cdots & x_{n=1}
\end{array}\right]
$$

6

where $a_{i j}\left(a_{i j} \geq 0\right) ;\left(i \in\{1,2, \ldots n\},(j \in\{1,2, \ldots m\}) ; a_{i j}\right.$ - of $i^{\text {th }}$ feature on $j^{\text {th }}$ criterion value

Step 2. The decision matrix is analysed to find its linear normalisation. 


$$
\beta_{i j}= \begin{cases}\frac{\alpha_{i j}}{i \operatorname{imax} \alpha_{i j}} & \text { if } j \in N_{b} \\ \frac{i \operatorname{min\alpha } \alpha_{i j}}{\alpha_{i j}} & \text { if } j \in N_{n b}\end{cases}
$$

7

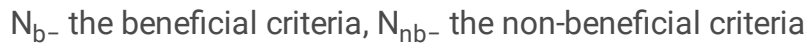

Step 3. Constructing a decision matrix with normalisation weights

$$
r_{i j}=w_{j} \beta_{i j}
$$

8

The weights requirement, wj, must be between 0 and 1 .

$w_{j}$ - weight criterion for $j^{\text {th }}$ alternative,

The aggregate of all weights equals one. i.e( $\left.\sum_{j=1}^{m} w_{j}=1\right)$

Step 4. Establishment of a counter-intuitive solution

$$
n s=\left[n s_{j}\right]_{1 \times m}
$$

9

$$
n s_{j}=\operatorname{minr}_{i}
$$

10

Step 5. Calculation of the Euclidean and Taxicab distances between characteristics using the counter-intuitive solution

$$
S_{i}=\sqrt{\sum_{j=1}^{m}\left(r_{i j}-n s_{j}\right)^{2}}
$$

11

$$
T_{i}=\sum_{j=1}^{m}\left|r_{i j}-n s_{j}\right|
$$

12

Step 6. Preparation of the matrix of relative assessment (Ra)

$$
R a=\left[\delta_{i k}\right]_{n \times n}
$$

13

$$
\delta_{i k}=\left(S_{i}-S_{k}\right)+\left(\psi\left(S_{i}-S_{k}\right) \times\left(T_{i}-T_{k}\right)\right)
$$

14

$\psi$ - Euclidean distances threshold function for two alternatives, $\mathrm{k} \in\{1,2, \ldots, \mathrm{n}\}$

$$
\psi(x)=\left\{\begin{array}{lll}
1 & \text { if } & |x| \geq \tau \\
0 & \text { if } & |x|<\tau
\end{array}\right.
$$

Page 10/17 
$\tau$ - threshold parameter value which lies between 0.01 and $0.05 . \tau=0.02$ is taken in this present study

Step 7. Estimation of relative assessment score

$$
\mathrm{Z}_{i}=\sum_{k=1}^{n} \delta_{i k}
$$

16

Step 8. By decreasing values, the assessment score $(\mathrm{Zi})$ is ranked. The highest $\mathrm{Zi}$ value represents the ideal score.

The following table summarises the weights for Optimization by Entropy that are included with CODAS.

For all experiments, the highest Relative Assessment score resulted in the greatest output responses. According to the COADS-Relative Assessment score, the input parameters (IP) at 60 ms welding time, Amplitude of $21 \mathrm{~Hz}$ and Pressure at $2.5 \mathrm{MPa}$ had the best output performance characteristics across all tests. According to the results, experiment twenty-five demonstrates that a higher CODAS-Relative Evaluation score of 2.444 is the appropriate parameter for assessment.

\section{Fractography of welded joints}

The 4-mm thickness lapped HDPE composite with 5\% PBI reinforced was used to get a better understanding of the impact of weld failure mode on joints. The joints were welded using the parameters stated above. The fractured surface of weld is vastly seen at the HAZ and not at the joints. The interlinking of materials gives more strength.

The SEM image 7 (a) were taken at the fractured surface of the Heat affected zone, to show the voids formed. The small porosity is formed due to difference in the solid/melt state at the welding zone. The small pores were the air spots that occurred due to the difference in viscosity of the materials at fusion zone and heat affected zone, Due to high frequency vibration, small air pockets formed as the heat inside creates an entanglement between the materials to form weld joint. These air pockets form the void during the solidifying state under the pressure. Figure 7b, $c$ and d shows the lap sheared surface of different parameters. The Fig. 7 (b) shows the weld shear of specimen 1 at low weld time, hold time, pressure and frequency. the sheared surface reveals the less pressure and the fusion was not proper. The Fig. 7 (c) shows the specimen of L25 shear. The weld strength was high and with high pressure, high frequency and more weld time. The figure $d$ shows the L16 sample shear fracture. The surface shows the deep grooves and tearing of joints.

The weld size, weld time and microstructure define the ultra-sonic weld strength. The microstructures formed were different at the fusion zone and heat affected zone. The excessive weld energy due to the higher welding time and Amplitude at the faying surface resulted in double fusion zones. The flashes were formed at the sides of the weld joint. The softening of material is found at the HAZ and resulted in the reduction of Shore D Hardness value. The flow direction of the weld is changed due to higher welding time and horn pressure. The thermo-oxidative and thermal degradation of HDPE composite created some pores inside the material and mostly seen at the heat affected zone. The moisture, environment, temperature and time had influenced the degradation of HDPE.

\section{Conclusion}

Twin screw machine is used to create filaments by intercalating the HDPE pellets and 5\% PBI fiber and made into pellets. Injection moulding methodology was used to fabricate the HDPE-5\%PBI composite specimens. The prepared composite was welded using ultra sonic welding machine. An L-27 Orthogonal array based on Taguchi method was adopted to find the best output strength of weld joint with varying input parameters. Utilizing entropy weight techniques, which were included into the CODAS approach, the output performance characteristics of the system were optimised, and the following conclusions were reached:

1. ANOVA studies revealed that the most important factor was Amplitude $(\mathrm{Hz})$ and weld time (ms) with a contribution factor of $32.39 \%$ and $31.6 \%$ in determining the Lap shear strength of the Ultra sonic welded HDPE-5\%PBI composite.

2. The investigation of Shore D Hardness shows that the weld time and pressure are the major contributors with $45.11 \%$ and $27.46 \%$.

3. The interaction of Weld time and Amplitude given the best interaction for both the outputs with contribution factor of 4.83 for shear strength and 5.81 for shore D hardness.

Page $11 / 17$ 
4. The microstructure observation reveals that the rise in amplitude $(\mathrm{Hz})$ leads to an increase in flowability and an increase in entanglement. Because to the existence of voids and porosities, the shear strength and hardness of the material were lowered.

5. CODAS show the relative assessment score for optimum conditions were achieved at $L 25$ for Weld time of $60 \mathrm{~ms}$, Amplitude of $21 \mathrm{~Hz}$ and Pressure of $2.5 \mathrm{MPa}$ with a score of 2.444

\section{Declarations}

Author Contributions: All authors are equally contributed to this article.

Funding: Not Applicable.

Data Availability: All data generated or analyzed during this study are included in this article.

Conflict of interest The authors declare that they have no known competing financial interests or personal relationships that could have appeared to influence the work reported in this article.

\section{References}

1. L. Wang, J. Qiu, E. Sakai, X. Wei, Compos. PART A (2015)

2. J. Sackmann, K. Burlage, C. Gerhardy, B. Memering, S. Liao, W.K. Schomburg, Ultrasonics (2014)

3. S. Krabbe, D.E. Achatz, T. Nieradzik, C. Gerhardy, W.K. Schomburg, Procedia Eng. 120, 598 (2015)

4. L. Oehm, S. Bach, J. Majschak, Ultrasonics 70, 204 (2016)

5. T. J. Ahmed, 37, 1638 (2006)

6. C. Ageorges, L. Ye, M. Hou, 32, (2006)

7. M. Hou, M. Yang, A. Beehag, Y. Mai, and L. Ye 47, 667 (2006)

8. J.S.U. Schell, J. Guilleminot, C. Binetruy, P. Krawczak, J. Mater. Process. Technol. 209, 5211 (2009)

9. F. Lambiase, A. Paoletti, A. Di Ilio, Int. J. Adv. Manuf. Technol. (2016)

10. A. Paoletti, F. Lambiase, A. Di Ilio, Int. J. Adv. Manuf. Technol. 83, 1395 (2016)

11. Y. Yan, Y. Shen, W. Zhang, W. Guan, (2017)

12. R.F. Zinati, (2015)

13. F. Lambiase, A. Paoletti, A. Di llio, (2015)

14. S. Hoseinlaghab, S.S. Mirjavadi, M.K.B. Givi, M. Azarbarmas, J. Mater. (2014)

15. J. Gao, C. Li, U. Shilpakar, Y. Shen, Int. J. Adv. Manuf. Technol. 87, 919 (2016)

16. H. Mohammadzadeh, H. Ramezani, H. Ghobadi, M. Ansari, S. Yari, M. Kazem, B. Givi, J. Manuf. Process. 21, 180 (2016)

17. S. Pappadà, A. Salomi, J. Montanaro, A. Passaro, A. Caruso, A. Maffezzoli, Aerosp. Sci. Technol. 43, 314 (2015)

18. S.A. Vendan, T. Chinnadurai, K.S. Kumar, N. Prakash, (2015)

19. M.R. Rani, K. Prakasan, R. Rudramoorthy, Ultrasonics 55, 123 (2015)

20. I.F. Villegas, Front. Mater. 6, (2019)

21. C. J. Nonhof, 3, 1177 (n.d.)

22. K.S. Suresh, M.R. Rani, K. Prakasan, R. Rudramoorthy, 186, 138 (2007)

23. I.F. Villegas, and H. E. N. Bersee 29, 112 (2010)

24. J. Tsujino, M. Hongoh, M. Yoshikuni, H. Hashii, 42, 131 (2004)

25. J. Tsujino, 1051 (1995)

26. A. Benatar, A. Mokhtarzadeh, 56, (2012)

27. C. Hopmann, A. Van Aaken, (2014)

28. K.D.J. Panneerselvam, Surf. Rev. Lett. (2019)

29. K.M. Shu, C. Shiang, W. Jun, and S. I. Wang 128, 381 (2010)

30. S. Liu, W. Lin, B. Chang, H. College, 18, 125 (1998)

Page $12 / 17$ 
31. S.J. Liu, I.T. Chang, S.W. Hung, Polym. Compos. 22, 132 (2001)

32. L.Y. Chen, Q. Zhi, J.C. Li, Z.X. Liu, P.C. Wang, Weld. J. 97, 17s (2018)

33. S.F. Raza, S.A. Khan, M.P. Mughal, Int. J. Adv. Manuf. Technol. 103, 2053 (2019)

34. Y. Gao, Q. Zhi, L.E.I. Lu, Z. Liu, (2018)

35. D.D. Jafrey, K. Panneerselvam, (2016)

36. G. Karthik Pandiyan, T. Prabaharan, D. Jafrey Daniel James, and V. Sivalingam, J. Mater. Eng. Perform. (2022)

\section{Figures}

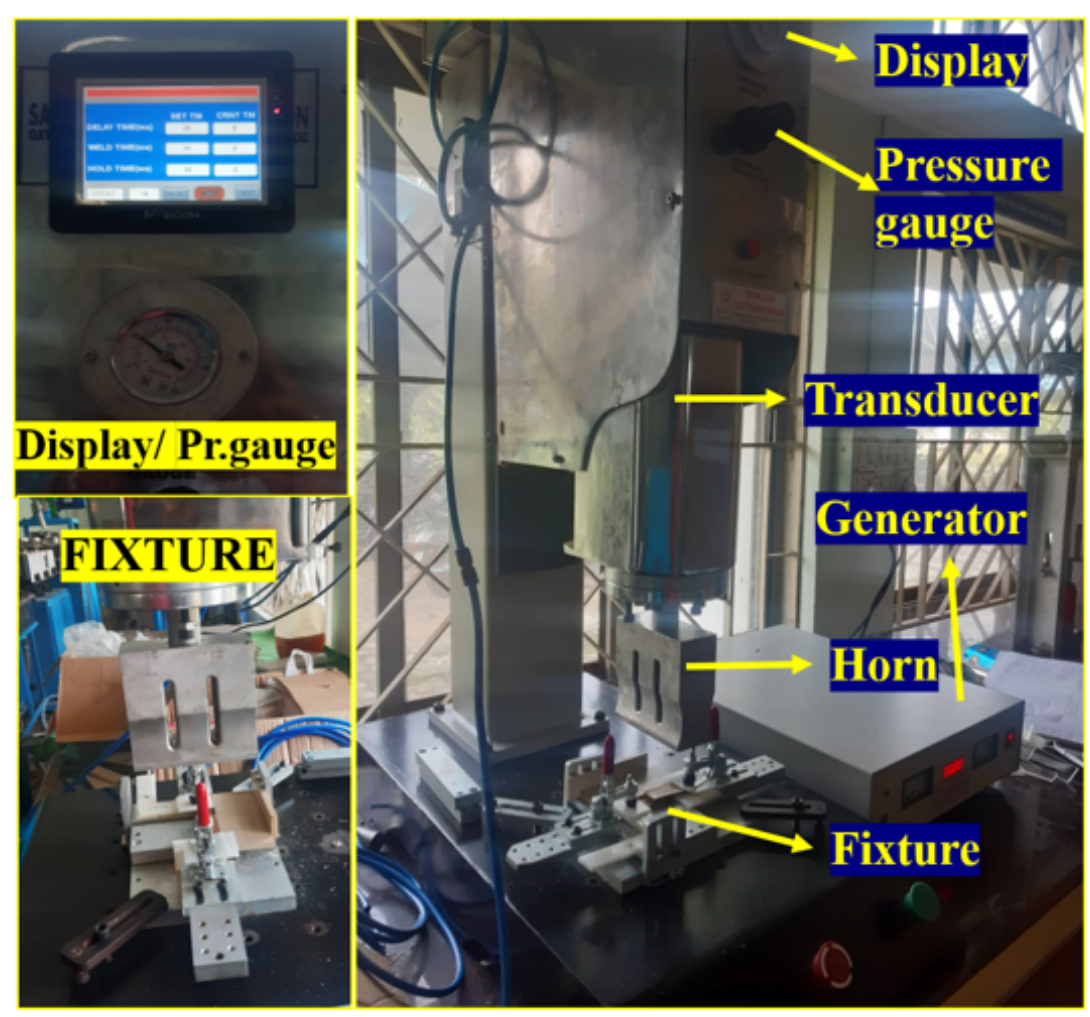

\section{Figure 1}

The ultra-sonic welding machine setup 


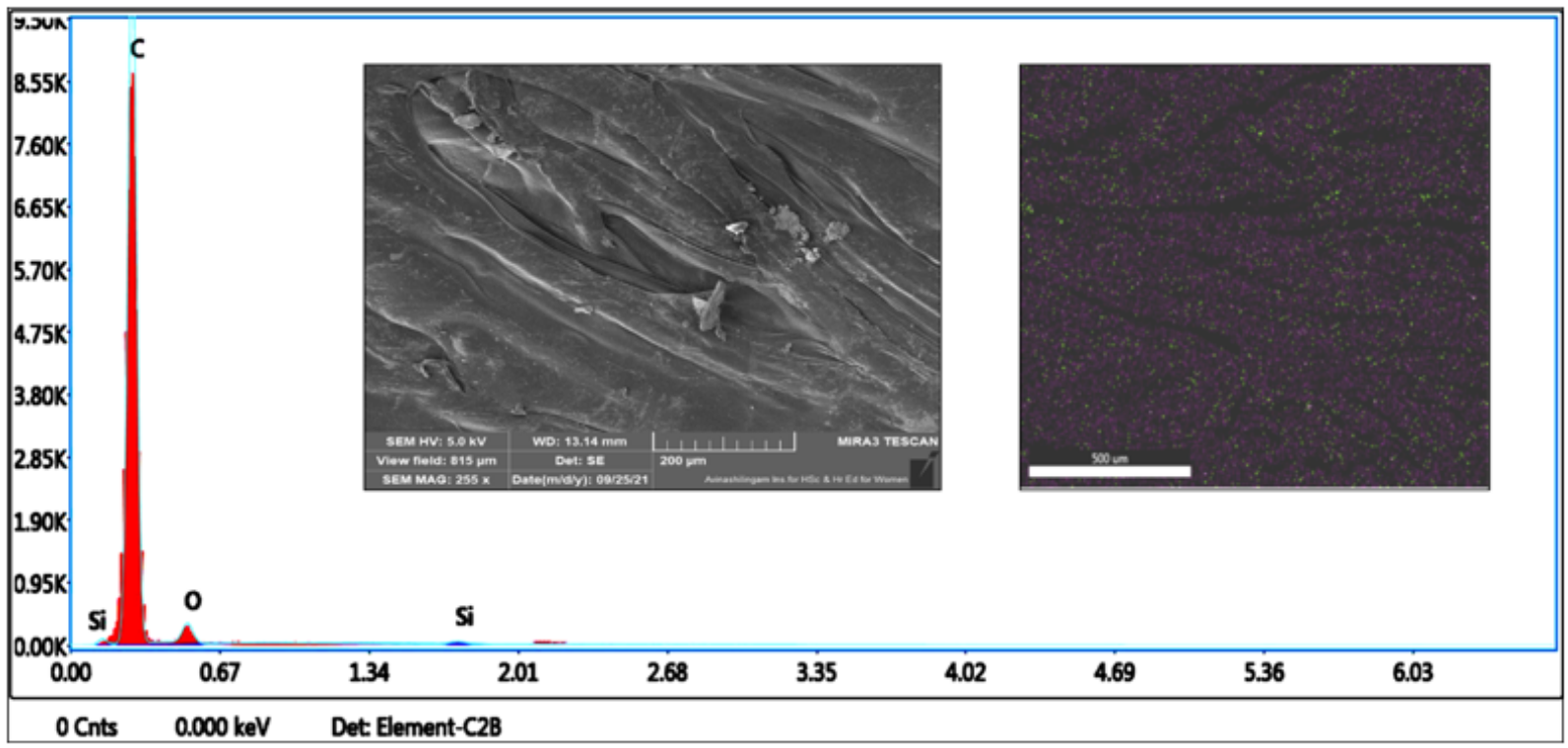

Figure 2

EDS image with elemental mapping of HDPE-5\% PBI composite.

\section{Figure 3}

a) HDPE-5\% PBI composite surface before weld, b) Weld surface at low Amplitude c) Weld surface at high Amplitude 


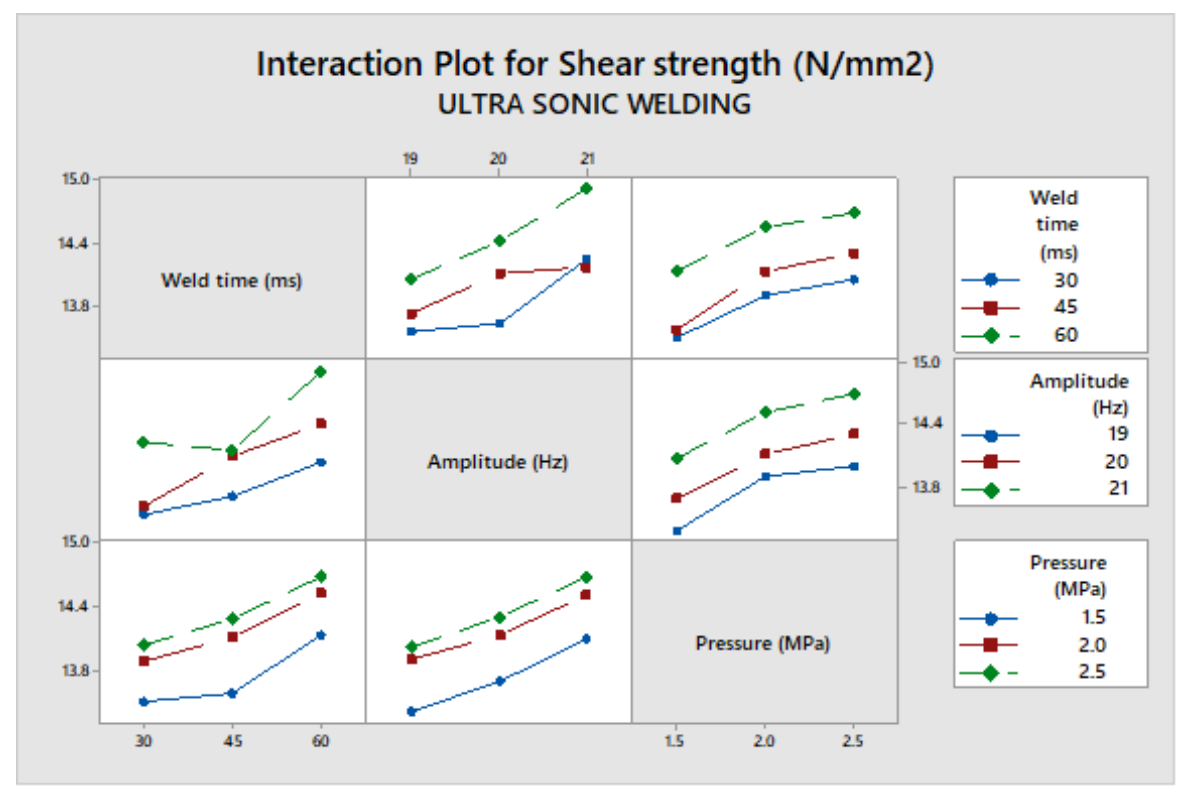

Figure 4

Interaction plot for shear strength for various factors done on USW.

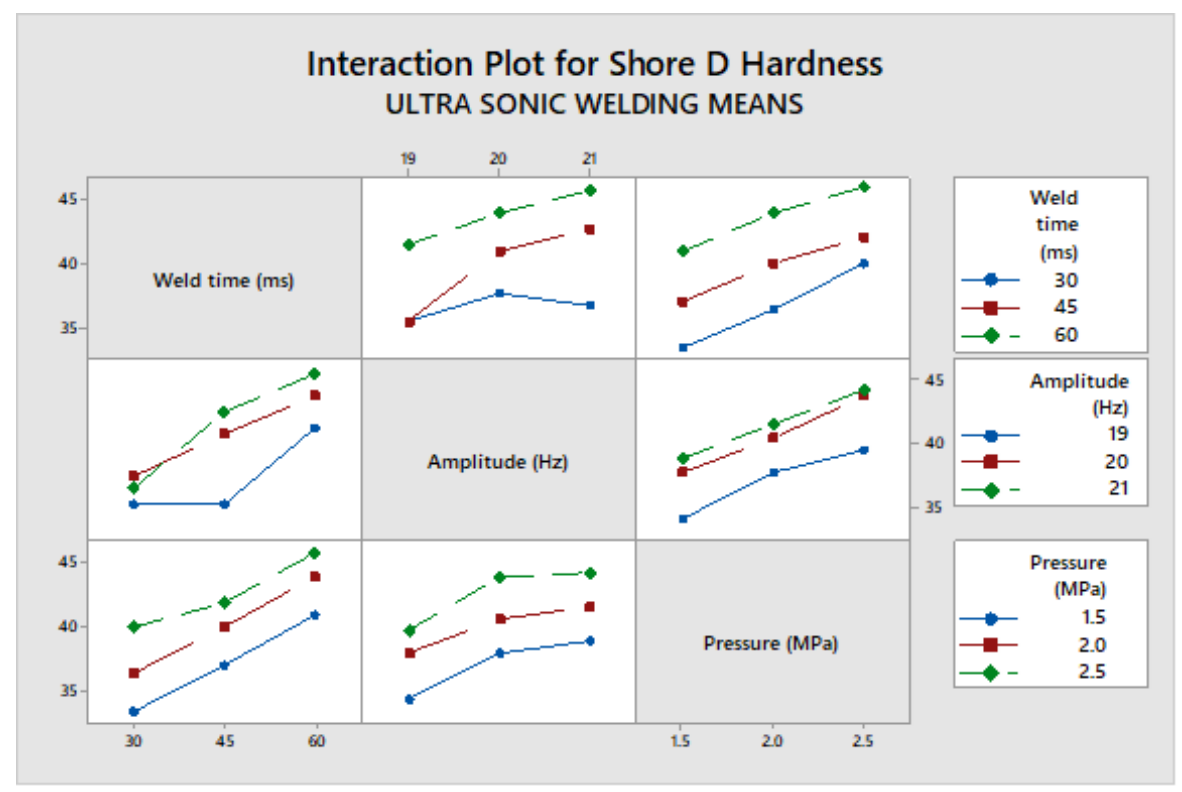

Figure 5

Interaction plot for shore D hardness for various factors done on USW. 


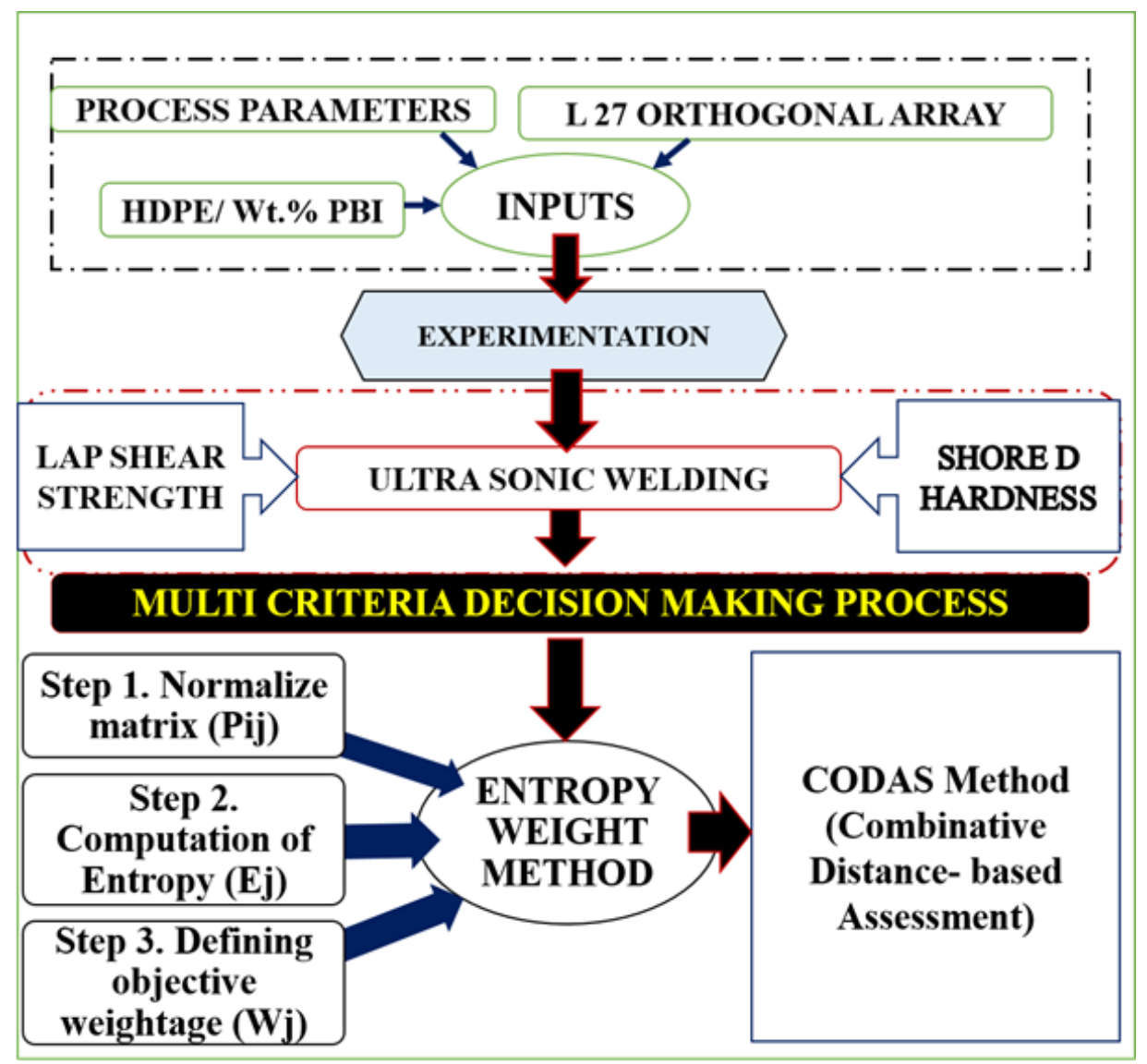

Figure 6

Experimental process of ultra-sonic welding.

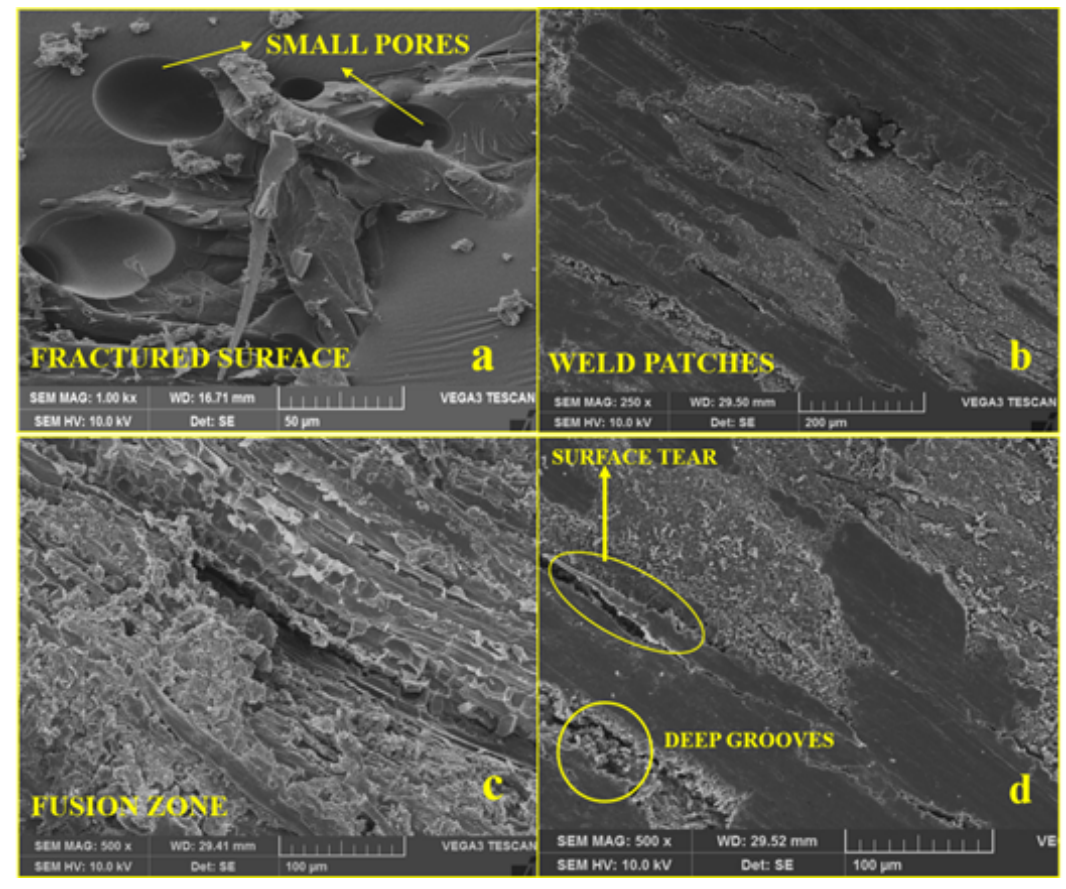

Figure 7 
a) Voids and pores found in the Fractured surface b) weld patches due to reduced weld time c) Fuzion zone at high amplitude d) Weld zone at low applied pressure 